\title{
Commentary: Blockade of activin type II receptors with a dual anti-ActRIIA/IIB antibody is critical to promote maximal skeletal muscle hypertrophy
}

\author{
Javier Durán and Manuel Estrada* \\ Program of Physiology and Biophysics, Faculty of Medicine, University of Chile, Santiago, Chile
}

Keywords: bimagrumab, ActRIIA/B receptors, skeletal muscle, anabolic steroids, myostatin/activin

\section{A commentary on}

Blockade of activin type II receptors with a dual anti-ActRIIA/IIB antibody is critical to promote maximal skeletal muscle hypertrophy

by Morvan, F., Rondeau, J. M., Zou, C., Minetti, G., Scheufler, C., Scharenberg, M., et al. (2017). Proc. Natl. Acad. Sci. U.S.A. 114, 12448-12453. doi: 10.1073/pnas.1707925114

\section{OPEN ACCESS}

Edited by:

Andres Trostchansky,

Universidad de la República, Uruguay

Reviewed by:

Juan Sebastian Carballal,

Universidad de la República, Uruguay

${ }^{*}$ Correspondence:

Manuel Estrada

endocell@gmail.com

Specialty section:

This article was submitted to

Experimental Pharmacology and Drug

Discovery,

a section of the journa

Frontiers in Pharmacology

Received: 14 February 2018

Accepted: 03 April 2018

Published: 19 April 2018

Citation:

Durán J and Estrada M (2018) Commentary: Blockade of activin type II receptors with a dual anti-ActRIIA/IIB antibody is critical to promote maximal

skeletal muscle hypertrophy.

Front. Pharmacol. 9:381.

doi: 10.3389/fphar.2018.00381
Balance in protein turnover influences the regulation of skeletal muscle mass (Schiaffino et al., 2013); it increases through anabolic processes and decreases owing to muscle wasting (as in diabetes and cancer), or muscle atrophy (as in aging and immobilization) (Basualto-Alarcón et al., 2014).

Endocrine and paracrine factors influence skeletal muscle growth by regulating different signaling pathways at the cellular and transcriptional levels. Transforming growth factor- $\beta$ members, Myostatin and Activin A, which mediate signal transduction through the Smad2/3 have been suggested as negative regulators of muscle growth (Massagué, 2012).

Muscle mass increases owing to myostatin and activin inhibition via a soluble anti-ActRIIB ligand trap (Lee et al., 2005). Interestingly, in myostatin-null mice, treatment with anti-ActRIIB antibody causes additive muscle hypertrophy, suggesting that ActRII receptor ligands regulate muscle growth (Lee et al., 2005; Lach-Trifilieff et al., 2014).

Because both ActRIIA and ActRIIB receptors regulate muscle mass, researchers at Novartis Institutes for Biomedical Research investigated the effect of a blockade of both ActRIIA and ActRIIB receptors with human anti-ActRII antibody "Bimagrumab" (BYM338) on skeletal muscle growth in mice. They suggested that only synchronous inhibition of both receptors induces a maximal anabolic response (Lach-Trifilieff et al., 2014).

Morvan et al. reported the crystal structures of bimagrumab Fv complex with human ActRIIA and ActRIIB ligand-binding domains, indicating its similar binding with both receptors, although their epitopes share a 65\% sequence identity. Nonetheless, bimagrumab has a 50-fold higher affinity for ActRIIB than for ActRIIA, probably owing to differences between several amino acid at the binding interface relevant for the interactions with bimagrumab (Morvan et al., 2017).

Since the blockade of ActRIIA or ActRIIB only partially blocks signaling downstream of myostatin and activin A stimulation, the effect of bimagrumab and its murine version (CDD866) was investigated on HEK293T/17 cells stably expressing Smad2/3; this effect was then compared with that of anti-ActRIIA or anti-ActRIIB antibodies. Inhibition of both receptors with a combination of these antibodies, bimagrumab, and CDD866, completely blocked Smad2/3 signaling induced by myostatin and activin A in comparison with the $30-50 \%$ inhibition with the either of the two antibodies. 
To compare the effect of single or synchronous blockade of ActRIIA and ActRIIB on muscle growth, mice were treated with anti-ActRIIA, anti-ActRIIB, both antibodies, or bimagrumab. Treatment with a combination of anti-ActRIIA and anti-ActRIIB antibodies or bimagrumab increased muscle strength and mass by $20-30 \%$, compared to the control, meanwhile, treatment with individual antibodies, increased by $10 \%$. This suggested that higher growth response results from blockade of both receptors, compared to effects of individual antibodies.

Recently, both murine models of cancer cachexia and bone healing after osteotomy suggest that either CDD866 or bimagrumab protects against both body weight and muscle mass loss resulting from anti-cancer therapy, with no effects on bone fracture healing (Hatakeyama et al., 2016; Tankó et al., 2016). Furthermore, clinical studies report that bimagrumab treatment increases muscle mass and strength in sporadic inclusion body myositis (Amato et al., 2014) and sarcopenia (Rooks et al., 2017a), both recovery of thigh muscle volume and decline in intermuscular adipose tissue after casting (Rooks et al., 2017b), and an improvement in both lean and fat mass, and insulin sensitivity in patients with insulin resistance (Garito et al., 2018).

Morvan et al. reported the role of ActRIIA and ActRIIB in muscle growth, representing valuable targets for blockade in pharmacological studies, along with a potential therapeutic alternative for patients with decreased muscle strength and mass. The clinical trials resource on the NIH website (https:// clinicaltrials.gov) indicates that the effect of bimagrumab was assessed in chronic obstructive pulmonary disease patients with cachexia and on weight loss in lung or pancreatic cancer patients; Bimagrumab increased muscle volume and is currently under clinical trials on patients who underwent hip fracture surgery or in patients with sarcopenia, overweight, and obesity, with type 2 diabetes.

Since muscle loss is also associated with significant reductions in anabolic hormones, we investigated the effects of androgens on cardiac and skeletal muscle cells. Myostatin decrease muscle mass, and influence bone health after androgen deprivation in mice; this was assessed through administration of soluble ActRIIB ligand traps (Koncarevic et al., 2010; Pan et al., 2016). Furthermore, myostatin levels are negatively regulated by androgens (Mendler et al., 2007) and in men, testosterone declines with age, suggesting that low plasma levels can cause or accelerate muscle- and age-related diseases. Some myostatin/activin members are upregulated with age (Brun and Rudnicki, 2015); however, a recent study suggests the opposite,

\section{REFERENCES}

Amato, A. A., Sivakumar, K., Goyal, N., David, W. S., Salajegheh, M., Praestgaard, J., et al. (2014). Treatment of sporadic inclusion body myositis with bimagrumab. Neurology 83, 2239-2246. doi: 10.1212/WNL.0000000000001070

Basualto-Alarcón, C., Varela, D., Duran, J., Maass, R., and Estrada, M. (2014). Sarcopenia and androgens: a link between pathology and treatment. Front. Endocrinol. (Lausanne) 5:217. doi: 10.3389/fendo.2014.00217 thereby presenting new changes regarding atrophic agents and loss of skeletal muscle mass (Schafer et al., 2016).

Physiological circulating levels of testosterone are important for ongoing muscle functions, but high concentrations induce cardiac and skeletal muscle hypertrophy (Basualto-Alarcón et al., 2014). Currently, meta-analysis and clinical trials show that low levels of testosterone are associated with metabolic syndrome, obesity and cardiovascular diseases (Wang et al., 2011). Because testosterone is a key physiological anabolic hormone, decreased plasma concentrations should be considered a primary cause for muscle loss and sarcopenia.

Under normal states, catabolic processes are balanced with anabolic processes; hence, it would be interesting to investigate the relationship between activation of anabolic pathways and inhibition of catabolic pathways to prevent muscle atrophy or to maintain and increase muscle mass. Myostatin levels negatively correlate with diverse muscle growth modulators (as insulinlike growth-factor-1 and growth hormone) that consequently potentiate myostatin/activin ligand atrophy (Schwarz et al., 2016). The pathways underlying hormonal regulation of muscle protein metabolism are complex and multifactorial. Anabolic hormones regulate protein synthesis via transcriptional and translational regulation through the Akt-mTORC1 pathway, which is inhibited by Smad2/3 (Sartori et al., 2014).

Hence, important aspects regarding interactions among different muscle growth regulators and drugs that inhibit ActRIIA/IIB receptors warrant further investigation. Pharmacological and preclinical studies aimed to identify integrated regulatory mechanisms that operate on muscle metabolism and growth could be used to promote healthy muscle adaptation and delay muscle loss associated with progression of muscle-related diseases and aging.

\section{AUTHOR CONTRIBUTIONS}

All authors listed have made a substantial, direct and intellectual contribution to the work, and approved it for publication.

\section{FUNDING}

This work was supported by Fondo Nacional de Desarrollo Científico y Tecnológico (FONDECYT) grant 1151118 (to ME).

\section{ACKNOWLEDGMENTS}

JD thanks to CONICYT for its PhD fellowship. youth. Cell Metab 22, 54-56. doi: 10.1016/j.cmet.2015.05.009

Garito, T., Roubenoff, R., Hompesch, M., Morrow, L., Gomez, K., Rooks, D., et al. (2018). Bimagrumab improves body composition and insulin sensitivity in insulin-resistant individuals. Diab. Obes. Metab. 20, 94-102. doi: 10.1111/dom.13042

Hatakeyama, S., Summermatter, S., Jourdain, M., Melly, S., Minetti, G. C., and Lach-Trifilieff, E. (2016). ActRII blockade protects mice from cancer cachexia 
and prolongs survival in the presence of anti-cancer treatments. Skelet Muscle 6:26. doi: 10.1186/s13395-016-0098-2

Koncarevic, A., Cornwall-Brady, M., Pullen, A., Davies, M., Sako, D., Liu, J., et al. (2010). A soluble activin receptor type IIb prevents the effects of androgen deprivation on body composition and bone health. Endocrinology 151, 4289-4300. doi: 10.1210/en.2010-0134

Lach-Trifilieff, E., Minetti, G. C., Sheppard, K., Ibebunjo, C., Feige, J. N., Hartmann, S., et al. (2014). An antibody blocking activin type II receptors induces strong skeletal muscle hypertrophy and protects from atrophy. Mol. Cell Biol. 34, 606-618. doi: 10.1128/MCB.01307-13

Lee, S. J., Reed, L. A., Davies, M. V., Girgenrath, S., Goad, M. E. P., Tomkinson, K. N., et al. (2005). Regulation of muscle growth by multiple ligands signaling through activin type II receptors. Proc. Natl. Acad. Sci. U.S.A. 102, 18117-18122. doi: 10.1073/pnas.0505996102

Massagué, J. (2012). TGF $\beta$ signalling in context. Nat. Rev. Mol. Cell Biol. 13, 616-630. doi: 10.1038/nrm3434

Mendler, L., Baka, Z., Kovacs-Simon, A., and Dux, L. (2007). Androgens negatively regulate myostatin expression in an androgen-dependent skeletal muscle. Biochem. Biophys. Res. Commun. 361, 237-242. doi: 10.1016/j.bbrc.2007.07.023

Morvan, F., Rondeau, J. M., Zou, C., Minetti, G., Scheufler, C., Scharenberg, M., et al. (2017). Blockade of activin type II receptors with a dual anti-ActRIIA/IIB antibody is critical to promote maximal skeletal muscle hypertrophy. Proc. Natl. Acad. Sci. U.S.A. 114, 12448-12453. doi: 10.1073/pnas.17079 25114

Pan, C., Singh, S., Sahasrabudhe, D. M., Chakkalakal, J. V., Krolewski, J. J., and Nastiuk, K. L. (2016). TGF $\beta$ superfamily members mediate androgen deprivation therapy-induced obese frailty in male mice. Endocrinology 157, 4461-4472. doi: 10.1210/en.2016-1580

Rooks, D., Praestgaard, J., Hariry, S., Laurent, D., Petricoul, O., Perry, R. G., et al. (2017a). Treatment of Sarcopenia with bimagrumab: results from a phase ii, randomized, controlled, proof-of-concept study. J. Am. Geriatr. Soc. 65, 1988-1995. doi: 10.1111/jgs.14927

Rooks, D. S., Laurent, D., Praestgaard, J., Rasmussen, S., Bartlett, M., and Tanko, L. B. (2017b). Effect of bimagrumab on thigh muscle volume and composition in men with casting-induced atrophy. J. Cachexia Sarcopenia Muscle 8, 727-734. doi: $10.1002 / j \mathrm{csm} .12205$
Sartori, R., Gregorevic, P., and Sandri, M. (2014). TGF $\beta$ and BMP signaling in skeletal muscle: potential significance for muscle-related disease. Trends Endocrinol. Metab. 25, 464-471. doi: 10.1016/j.tem.2014.06.002

Schwarz, N. A., McKinley-Barnard, S. K., Spillane, M. B., Andre, T. L., Gann, J. J., and Willoughby, D.S. (2016). Effect of resistance exercise intensity on the expression of PGC-1alpha isoforms and the anabolic and catabolic signaling mediators, IGF-1 and myostatin, in human skeletal muscle. Appl. Physiol. Nutr. Metab. 41, 856-863. doi: 10.1139/apnm-2016-0047

Schafer, M. J., Atkinson, E. J., Vanderboom, P. M., Kotajarvi, B., White, T. A., Moore, M. M., et al. (2016). Quantification of GDF11 and Myostatin in Human Aging and Cardiovascular Disease. Cell Metab. 23, 1207-1215. doi: 10.1016/j.cmet.2016.05.023

Schiaffino, S., Dyar, K. A., Ciciliot, S., Blaauw, B., and Sandri, M. (2013). Mechanisms regulating skeletal muscle growth and atrophy. FEBS J. 280, 4294-4314. doi: 10.1111/febs.12253

Tankó, L. B., Goldhahn, J., Varela, A., Lesage, E., Smith, S. Y., Pilling, A., et al. (2016). Does activin receptor blockade by bimagrumab (BYM338) pose detrimental effects on bone healing in a rat fibula osteotomy model? Calcif. Tiss. Int. 99, 310-321. doi: 10.1007/s00223-016-0148-0

Wang, C., Jackson, G., Jones, T. H., Matsumoto, A. M., Nehra, A., Perelman, M. A., et al. (2011). Low testosterone associated with obesity and the metabolic syndrome contributes to sexual dysfunction and cardiovascular disease risk in men with type 2 diabetes. Diab. Care 34, 1669-1675. doi: 10.2337/dc10-2339

Conflict of Interest Statement: The authors declare that the research was conducted in the absence of any commercial or financial relationships that could be construed as a potential conflict of interest.

The reviewer JC and handling Editor declared their shared affiliation.

Copyright ( $\odot 2018$ Durán and Estrada. This is an open-access article distributed under the terms of the Creative Commons Attribution License (CC BY). The use, distribution or reproduction in other forums is permitted, provided the original author(s) and the copyright owner are credited and that the original publication in this journal is cited, in accordance with accepted academic practice. No use, distribution or reproduction is permitted which does not comply with these terms. 